issn: $1808-799 \mathrm{X}$

ano 5 - número 5 - 2007

ensaio

“PARA UN TIEMPO INESPERADO, UNA EDUCACION INESPERADA”[1]

Germán Cantero

El mundo al revés nos enseña a padecer la realidad en lugar de cambiarla, a olvidar el pasado en lugar de escucharlo, a aceptar el futuro en lugar de imaginarlo;

(...) En su escuela (...) son obligatorias las clases de impotencia, amnesia y resignación. Pero está visto que no hay desgracia sin gracia, ni cara que no tenga su contracara, ni desaliento que no busque su aliento. Ni tampoco hay escuela que no encuentre su contraescuela". Eduardo Galeano: "Patas arriba -La escuela de un mundo al revés".

Compartir con Uds. reflexiones sobre la responsabilidad social de la educación, con Uds., que próximamente serán los primeros egresados de una Maestría en Educación en esta tierra austral y, por ello, significados quizás con más fuerza que hoy como referentes 
regionales para pensar y transformar la educación del sur patagónico, me ha interpelado pedagógicamente.

La pregunta que me hago es: ¿desde dónde hablar a otros colegas sobre responsabilidad social en educación, si probablemente nos separa una distancia generacional que da cuenta de recorridos existenciales diferentes en la construcción de nuestras respectivas subjetividades. ¿Hasta qué punto habrá incidido en esta construcción el tránsito por contextos históricos no compartidos entre nosotros y por otros vividos simultáneamente pero desde historias diferentes?

Para atisbar juntos algunas respuestas en este sentido, les propongo reflexionar sobre la atmósfera intelectual en la que probablemente transcurrió la formación de grado y postgrado de la mayoría de Uds. en el contexto de acontecimientos y lecturas que compartimos. La propuesta es la de hipotetizar sobre las expectativas de futuro que construimos en ese trayecto, sobre lo que por entonces era esperable y sobre los emergentes históricos inesperados que luego sobrevinieron. Se me ocurre que desde estas sorpresas, las de una historia que sigue insistiendo en mostrarse abierta, que desde este re-examen de la memoria, podríamos entonces compartir reflexiones sobre el lugar subjetivo desde el cual hoy nos planteamos nuestras responsabilidades como educadores y sobre posibles resignificaciones al respecto

Por aquellos años, ¿recuerdan?, muchas cátedras comentaban la obra de Francis Fukuyama "El fin de la historia y el último hombre" (1992), un texto emblemático de toda una operación semántica global que trataba de construir discursivamente un horizonte de expectativas a escala planetaria: de euforia invasiva para unos pocos y de resignación y/o naturalización disciplinada y productiva para las grandes mayorías. Sin embargo, influenciados por esta prédica mediática, unos y otros parecían haber llegado a una coincidencia: el libre mercado como sistema económico y la democracia liberal como régimen político eran los límites de lo pensable e imaginable para el futuro de la humanidad.

El planeta comenzaba a organizarse geopolítica y socialmente sobre la base de nuevas categorías y fronteras simbólicas demarcatorias entre lo interior y exterior, lo seguro e inseguro y lo político y no político. En los bordes del mundo satisfecho se aceleraban las 
luchas por los recursos de un modelo de acumulación insaciable e insustentable: el Golfo (1990/1991); los Balcanes (1998/99); Afganistán (2001); Irak (2003)... Así se llega hoy, sin riesgos que merezcan consideración y debilitados a niveles patéticos los controles internacionales, a la guerra preventiva como expresión del grado de impunidad de la hegemonía triunfante. Mientras, la humanidad toda asiste al mega espectáculo del horror. Al comenzar el siglo, la misma estética mediática confundía, en una gigantesca vidriera de los cambalaches de pantallas y monitores, el fuego de las explosiones que consumían vidas sin rostro y culturas milenarias con el fuego de artificio con el que se festejaba, en ilusorio paréntesis, el cambio de milenio. En Medio Oriente, las opciones de genocidio y de autoinmolación parecen estar ganando terreno y el horizonte de la paz sigue alejándose hasta casi perderse. A veces, el espectáculo se ha trasladado a otros escenarios, presentados como más exóticos y extraños, para mostrar, por ejemplo, al Africa sursahariana desfalleciendo en cíclicas hambrunas, matanzas masivas y epidemias, como aleccionadora muestra de lo que queda de pueblos y naciones más débiles, una vez que la voracidad colonial se ha saciado en parte. De todo esto pueden hablar también los pueblos originarios americanos.

A comienzos de los '90, los que hoy son sus alumnos tal vez eran, en su mayoría, sólo niños de educación inicial y primaria, y se asomaban por entonces a un mundo que les proponía naturalizar el dolor humano como espectáculo. También nosotros éramos sometidos a ese montaje comunicacional.

Diez años más tarde, cuando algunos de estos alumnos completaban su educación secundaria y otros ingresaban en nuestras instituciones de educación superior; cuando algunos de Uds. quizás estaban ya proyectando su formación de postgrado, pudimos contemplar cómo el horror ingresaba fugazmente dentro de las fronteras de la opulencia, haciendo blanco en sus símbolos emblemáticos de poder económico y bélico. La coartada para una nueva ola de ocupación de territorios estratégicos a sangre y fuego estaba servida. Se montaba entonces una ingeniería comunicacional que intentaba legitimar el dolor de los pueblos avasallados estigmatizándolos moralmente como expresión del mal. Hoy, alcanzados los objetivos nunca confesados, pero consciente de que se ha ido demasiado lejos frente a la opinión pública mundial, la propia hegemonía comienza su depuración, haciendo depositarios de sus excesos a los gerentes visibles de la tarea sucia.

Sin embargo, además de los réditos económicos y políticos de todo este proceso, habría 
que preguntarse hasta qué punto otro logro más sutil se ha obtenido: instalar en la subjetividad de las multitudes un miedo visceral ante la exhibición desembozada de un poder global que no repara en medios para satisfacer su propia dinámica de acumulación. Quizás, algo análogo a lo que aún se observa en nuestra sociedad, a casi un cuarto de siglo del fin de la última dictadura. Sin embargo, entre nosotros el miedo no se infiltra a través del espectáculo virtual de un mundo anónimo y lejano, sino a través de la red de vínculos comunicacionales y afectivos con las propias víctimas del horror y sus familias, con rostros queridos y cercanos.

Lo mismo ocurrió en los '90 con los efectos del modelo global que de tal manera se impuso. Estos no llegaron sólo a través de pantallas, como dolores y privaciones distantes, ingresaron en la cotidianeidad de las familias argentinas alterándola brutalmente con la precarización del trabajo o el desempleo sine die de los que una vez fueron trabajadores. La exclusión como destino se instaló así en el imaginario de una parte de la población y nuevas generaciones crecieron con esta expectativa como fatalidad. Miles de niños fueron privados de contención y muchos empujados a la calle en búsqueda de la sobrevivencia cotidiana. La lucha social se territorializó en las ciudades y surgieron los piquetes como estrategia colectiva en procura de visibilidad para la protesta y de nuevas condiciones de negociación con el viejo clientelismo político. Simultáneamente, se afianzaron estrategias individuales y familiares de subsistencia diaria que involucraron a niños y adultos; dando lugar a una provocativa categoría sociológica: el cazador urbano, como constructo patético de una época. Otros sectores sociales, en el campo y la ciudad, probaron estrategias similares en búsqueda de su propia visibilidad ante la crisis de las instituciones de un Estado que durante una década justificó su corrimiento a través del discurso de la subsidiariedad. Paralelamente, la especulación financiera se constituyó en motor de la economía y en cultura que unificó en una misma lógica a las estrategias de acumulación más pequeñas y a las más sofisticadas, al modesto jubilado y al gran propietario. El nuevo siglo amaneció así en la Argentina iluminando un país cuya sociedad y geografía exhibía los índices de mayor desigualdad del continente; el mismo país que un día se ufanara por sus niveles de integración y movilidad social.

Este escenario se proyectaba entonces como horizonte tendencial en el contexto del discurso único de la poshistoria. Para las grandes mayorías, lo esperable era la continuidad del espectáculo del horror global y un presente indefinido de carencia y falta de reconocimiento en lo local. Para algunas minorías intelectuales, el desencanto con las promesas de la modernidad, estaba dejando de ser una benéfica perdida de ilusiones y se estaba transformando en una peligrosa pérdida de sentidos (N. Lechner, 1988:185). Para 
las otras minorías, las beneficiarias de este modo de acumulación salvaje, lo esperable era que esta expansión se sostuviera pero con exención de toda responsabilidad por los costos colaterales que le son inherentes (entiéndase: sociales, biológicos, ecológicos, culturales y políticos), por estas externalidades no considerables dentro la lógica del modelo. Hubieran deseado, eso sí, menos conflictos y sobresaltos; aquella ilusión de previsibilidad a largo plazo que prometía una era de pospolítica.

Hasta aquí algunos hechos y procesos que quizás aporten a una reflexión sobre su incidencia en la constitución de las subjetividades desde las cuales nos paramos hoy frente a nuestra responsabilidad como educadores.

Les propongo ahora pasar de los hechos a los discursos, discursos que nos atravesaron durante aquellos años. Para ello hice para Uds. un ejercicio: retrotraerme diez años atrás (1997) y, releyendo artículos de algunos intelectuales argentinos y extranjeros, proponerles una apretada síntesis sobre la lectura de una época que estos autores hicieron desde la prensa de ese año. Se trata de un recorte arbitrario en muchos sentidos que, sin embargo, se plantea desde el supuesto de que éstos $u$ otros textos similares y sus contextos, constituyen nódulos de significación que, en clave de lo esperado e inesperado, remiten a toda una red discursiva que probablemente haya incidido en la construcción de la subjetividad de todos nosotros. Discursos como éstos tal vez hayan incidido en un modo de pensar y de desear, quizás, como ya dije, con las diferencias atribuibles a nuestras respectivas historias personales y generacionales.

En esta muestra, que considero expresiva de las preocupaciones y del clima intelectual de hace una década, la justicia se describía como aquejada de una suerte de timidez universal; el poder político aparecía como propiedad privada de los mandatarios; las instituciones eran percibidas como confecciones a la medida de las ambiciones y designios de los políticos de turnos; las decisiones de gobierno parecían más inspiradas en el interés de preservar un régimen que en imperativos políticos y morales sustantivos. En el mundo opulento esto comenzaba a expresarse como rechazo xenófobo al diferente; primero, construyendo muros simbólicos, luego, más recientemente, levantando otros de acero. Por entonces se afirmaba que las sociedades habían ingresado a una cultura posmoralista reciclada en la lógica del espectáculo; sobre ella sobrevolaba el irracionalismo y la violencia. 
En Argentina toda referencia a la ética pública era decodificada en clave de corrupción (eran los años de la exhibición obscena y frívola de una dirigencia política devenida en farándula). Aquí y más allá, la propia verdad aparecía travestida en verosimilitud, propuesta por una información que, desde el hiperespacio, difícilmente era refutable en tiempo real, apoyándose a veces en la manipulación estadística. Los medios masivos de comunicación se especializaban en usar un tiempo precioso en banalidades capaces de ocultar cosas preciosas 0 , dicho de otro modo, en banalizar lo que podía ser problemático. Una pizca de utopía era alentada apenas como recurso terapéutico, todo lo demás era caratulado de extremismo, sueño o neurosis, y la propia rebeldía se toleraba en cuotas incapaces de afear las prácticas políticas. El mundo hegemónico propiciaba, fronteras adentro, una política estéticamente deseable por la racionalidad de su domesticación; fronteras afuera, comenzaba a legitimar la barbarie para con los extraños, a los que desconocía y subestimaba en su necedad y soberbia autista.

Los intelectuales nacionales y extranjeros que, desde su diversidad y diferencias, me permitieron reconstruir el escenario de ese año, como expresión del apogeo neoliberal, son en su mayoría conocidos por todos nosotros. Por orden "de aparición" en la síntesis precedente, ellos son: Natalio Botana, Julio Halperín Donghi, Guillermo O’Donnell, Teun Van Dijk, Enrique Marí, Tomás Abraham, Jean Baudrillard, Pierre Bourdieu, Jean-Paul Fitoussi y Pierre Rosanvallon. Claro que el diario que me sirvió de fuente, tomó distancia de uno de ellos con el calificativo usual para quienes irritan intereses hegemónicos: "polémico"; se trataba de Pierre Bourdieu.

Seguramente no todos fuimos afectados de la misma forma por estos y muchos otros discursos similares que llenaron estantes enteros de bibliotecas privadas y públicas y archivos en distintos soportes. Pero más allá que hoy nos refiramos a ellos en términos de pasado o aún de presente, difícilmente alguno de nosotros podrá afirmar que salió indemne de la atmósfera intelectual y emocional de aquellos años.

Quizás por eso, más recientemente, procesos que se venían gestando desde décadas y aún centurias, nos sorprendieron a muchos como acontecimientos. Sin duda que su manifestación obedeció además a factores también imprevisibles y coyunturales, pero su expresión tuvo el efecto de lo inesperado. 
También sorprendió a muchos el grado de cinismo y violencia sin límites que ha alcanzado una hegemonía global devenida en dominación cada vez más desembozada; como asimismo, la furia de una naturaleza también violentada por un modelo depredatorio que ya no puede ocultar su insustentabilidad.

Pero mientras el mundo global (del que obviamente somos parte) nos ha sorprendido, quizás, por el extremo al que han llegado sus tendencias más perversas, un mundo más próximo (al que también pertenecemos), el de América Latina, nos ha sorprendido esta vez gratamente, por nuevas y creativas manifestaciones de que otro mundo es posible.

Desde la selva mexicana de Lacandona, desde la experiencia milenaria de la cultura maya, un reclamo de cinco siglos aflora a la superficie de la política; procede de los más pobres entre los pobres, de los distintos entre los diferentes y plantea, desde una poética y ética propia, con sorprendente creatividad teórica y práctica, una propuesta "que afecta a la esencia misma del poder político y de las formas de legitimación"[2] .

Desde Brasil, el Movimiento de los Sin Tierra, no sólo sostiene desde hace décadas una lucha por el derecho a la tierra, "por plantar la agroecología en el corazón del mundo"[3], sino que alberga en sus asentamientos, más de mil escuelas públicas elementales, decenas de escuelas medias y una escuela de educación superior como lugares de enunciación de palabras liberadoras. También desde Brasil, Porto Alegre se convierte en la capital de un planeta que piensa en clave alternativa.

Argentina, por su parte, preocupa al mundo de la pospolítica con expresiones que rompen el formato de las instituciones liberales: piquetes, asambleas barriales, cacelorazos, fábricas recuperadas, puebladas en defensa de la ecología van instituyendo desde la horizontalidad atajos a las trampas de la democracia representativa.

Más recientemente, América Latina vuelve a sorprender: en Argentina, Brasil, Chile y Uruguay, retrocede al menos el discurso liberal y con la gramática de una suerte de realismo mágico de la política, con destellos de oro y fango, de manera torpe y contradictoria, se asciende una cuesta por ahora sinuosa. Quizás en la cima el camino vire 
en otra dirección.

Podría afirmarse que estos procesos, envueltos en la telaraña del sistema, enredados en sus límites, son al mismo tiempo, la expresión de su crisis y su fuerza más activa; la que dirime "en el poder político la lucha que tiene lugar en las entrañas del sistema". Y este sistema, parafraseando a Raymond Williams, produce y limita a la vez sus propias formas de contrasistema. Pero por ser precisamente y al mismo tiempo, expresiones de su crisis, estos procesos sorprenden de tanto en tanto a los ortodoxos de la teoría política, rompiendo el tejido de la tela de una historia que, desde su escepticismo, imaginaban previsible. Vale la pena entonces, coincidiendo con Carlos Gabetta, "participar y criticar", tratando "de orientarse en la bruma" de la propia crisis y acompañar, de la manera que cada uno elija, estas experiencias de "política masiva y potente, caótica y desesperada"[4].

En este sentido hay países que han comenzado a romper la tela, redoblando su apuesta política: Venezuela y Bolivia, cada una con una creatividad que sacude a la razón indolente y perezosa[5], hablan de revolución; una, desde la sombra de Bolívar, la otra, desde la fuerza y el dolor acumulado por 500 años de desprecio y explotación de sus pueblos originarios; Ecuador comienza a esbozar un intento semejante.

Frente a todo esto, para algunos desconcertante, para otros fascinante y para todos, tal vez sorprendente, los educadores quizás podamos hacer una contribución que vaya más allá de lo imaginable, de lo pensable desde la razón pacata.

Algunos apostamos a que esto es posible y vale la pena; porque romper la telaraña de la hegemonía depende de una correlación indecible pero decisiva: la que plantea, por una parte, la propia crisis de la gran araña que teje y la que, por la otra, depende de las posibilidades y limitaciones de la cultura política de los pueblos.

Estoy convencido de que precisamente aquí está nuestro lugar. De nosotros depende tomar la posta de los que creyeron lo suficiente para combatir y resistir, para intentar contribuir a una transformación de esta cultura política. 
Un modo de avanzar en esta dirección es seguir construyendo experiencias educativas múltiples que puedan sorprender a los que tienen las alas cortadas por el miedo o por la mezquindad, como se lamentaba Benedetti, refiriéndose a las secuelas de las viejas pero actuantes dictaduras.

Construir para un tiempo inesperado una educación inesperada que acompañe las esperanzas y las luchas de aquellos que han esperado tanto y siguen esperando, podría implicar resignificar, desde otra intencionalidad pedagógica y política, la actual crisis de la educación y de la escuela. Si nos ubicamos desde la perspectiva de los intereses del sistema dominante, se podría sostener la hipótesis de que la crisis de la institución escolar reside en su creciente incapacidad de sujetar. El escaso éxito de las escuelas en responder al viejo mandato reproductor, se expresa en los cotidianos desbordes de los sujetos mal sujetados. Simultáneamente, algunas instituciones dan signos de una vitalidad renovada en la medida en que los actores escolares, en casos por ahora muy singulares, se plantean como alternativa potenciar su capacidad de aportar a la construcción de sujetos autónomos, de sujetos políticos. Este giro pedagógico requiere construir propuestas y proyectos más desde la escucha de estos sujetos que desde el arbitrario oficial instituido.

Esto implica, a su vez, optar por una pedagogía que se despliegue desde un esfuerzo genuino, aunque siempre insuficiente, por descentrarnos de nuestras propias referencias, para ubicarnos desde la cultura, saberes y necesidades de los alumnos y desde el reconocimiento profundo y cotidiano de sus medios de origen.

Este giro pedagógico supone, además, una apuesta fuerte por el potencial autoeducativo de estos sujetos, sin flojeras asistencialistas como ya lo planteara Freire. Como una vez me dijo una maestra, esto requiere una actitud de investigación permanente que permita que sean ellos, los alumnos, los que marquen el camino pedagógico a seguir, en diálogo con nuestra intencionalidad crítica.

Seguir este camino conduce a pararnos con autonomía y actitud saludablemente transgresora, para construir con los alumnos y demás sujetos institucionales y sociales, un currículum que, desde las prácticas del aula y desde las propias prácticas de gobierno escolar, les ayuden a integrarse a un mundo con aptitud para hacer valorar su trabajo, 
luchar por sus derechos y participar de la construcción de un mundo alternativo; a sabiendas que esta construcción es mucho más compleja y ardua de que lo que imaginaban algunos pensadores del siglo XIX y que los tiempos de la misma rara vez transcurren al ritmo de las expectativas y urgencias de una generación.

No sólo se trata acompañar los procesos emancipatorios que pujan desde la dignidad de los nadies por su reconocimiento; se trata también de atender a otros sectores cuya emancipación no pareciera ni tan necesaria ni tan clara: son nuestros alumnos de las clases medias, empujados -con las mejores intenciones de quienes más los quieren- para ser meros recursos de un orden que sólo les propone una carrera a los codazos para triunfar como productores y consumidores, sin siquiera tener los elementos para preguntarse si ese orden merece sus vidas a tiempo completo.

Acompañar los procesos emancipatorios de los alumnos requiere recuperar para la educación el acerbo del pensamiento pedagógico crítico que, desde América Latina y desde fuera de ella, alimentaron las experiencias más potentes que recuerda nuestro continente, pero también las críticas más radicales. Experiencias y críticas, vale la pena recordarlo, amasadas en este país y Latinoamérica toda, entre el dolor de la lucha y el goce anticipatorio de horizontes utópicos. Este patrimonio fue descalificado a poco de recuperadas nuestras frágiles democracias, sin beneficio de inventario alguno y con sospechoso apresuramiento (J. Tamarit; 1992:7). Suturar esta herida, soldar esta fractura de nuestra memoria pedagógica, para articularla con toda la riqueza de los aportes que se sucedieron hasta la actualidad es una deuda pendiente con nuestra sociedad. Eso sí, esta deuda exige ser saldada, como sólo cabe en la universidad, desde un debate sin contemplaciones.

Tampoco sería posible recuperar para Argentina y para este continente pedagogías liberadoras sin incorporar a la memoria colectiva docente y a los currículos el patrimonio de la historia olvidada y a veces prohibida de América Latina. Cómo proponer una educación ciudadana crítica, cómo contribuir a la emergencia de sujetos políticos individuales y colectivos autónomos, sino los conectamos con las luchas que los precedieron y que narraron los autores acallados; desde Mariátegui y Martí en adelante, para avanzar en lo que ellos soñaron: una segunda independencia o, en términos de $\mathrm{E}$. Dussel, una segunda emancipación. 
Esta segunda emancipación que, como afirmaba Simón Rodríguez, debía ser fundamentalmente una emancipación del pensamiento, debe sostenerse también desde un conocimiento gestado al calor de los problemas y necesidades de este país y de este continente. Cada historia de producción de conocimiento es tributaria de preocupaciones específicas, de una sensibilidad que se desarrolla en contacto con un entorno de rostros, voces y sucesos concretos que conmueven e incitan a una reflexión crítica situada. Por eso solemos afirmar que detrás de cada libro hay una biografía. Desde una matriz de saberes así gestados, es necesario entonces abrirse al pensamiento universal, que por analogía o diferencia, enriquece, matiza y profundiza el vuelo autónomo y creativo, en un mundo global que nos quiere uniformar los cuerpos y homogeneizar las ideas.

Esto vale también para la investigación: sus referentes empíricos son los niños, jóvenes y adultos concretos que hoy desafían nuestra capacidad de comprender, explicar y aportar a la construcción de teoría; de fundamentar propuestas o, al menos, elaborar preguntas más pertinentes. Sus referentes son también las escuelas argentinas y latinoamericanas en toda la diversidad de sus experiencias, algunas de ellas verdaderamente alternativas $\mathrm{y}$, a veces, desesperadamente solas; sus universos primarios a comprender son la diversidad de sus culturas y entornos sociales. Desde los conocimientos construidos desde estas especificidades, entonces sí es necesario recurrir a ese otro universo enorme y rico que nos nutre desde sus semejanzas y contrastes.

Pero para construir currículos desde los problemas de los sujetos que los requieren, es preciso considerar otra opción epistemológica: la del pensar desde la complejidad. Los problemas no son temas de conocimiento sino totalidades que se resisten a la disección de las disciplinas y a los abordajes fragmentarios. Quizás para ello sean necesarios también otros giros epistemológicos desde los cuales revisar el carácter helenocéntrico y eurocéntrico de nuestros saberes; desde los cuales suturar las fisuras convencionales entre los diferentes campos del conocimiento; desde los cuales deponer la soberbia hegemónica de la racionalidad analítica moderna y abrirse a una multiplicidad de saberes y vías no convencionales de conocimiento.

Abordar sus problemas es hacerlos nuestros; esto implica que entre nosotros y los alumnos el conocimiento no se interponga como una mediación sino que, siendo un conocimiento propuesto desde nuestra sensibilidad por sus necesidades, sea el motivo de un vínculo construido a través del afecto. 
Uds., queridos maestrandos y maestrandas serán, como dije al comienzo, los referentes regionales de una provincia que se propone levantar un nuevo faro del fin del mundo: el de una institución universitaria que, sin pretender un iluminismo extemporáneo, se encienda en cambio a través de la mutua elucidación que se establezca en el encuentro de sus intelectuales y la voz, los saberes y las necesidades de los fueguinos. Dense a Uds. mismos el permiso de diseñar esta universidad desde sus especificidades; hagan una universidad a la medida de Uds. y de este país, como lo hizo Córdoba en el 18 y Brasilia en el 61. En síntesis, dense el permiso para ser maestros.

Cuando muchos de Uds. o sus padres llegaron a esta tierra quizás sintieron algo de lo que José Martí expresó al llegar a Guatemala: "Yo llegué meses hace a un pueblo hermoso: llegué pobre, desconocido y triste. Sin perturbar mi decoro, sin doblegar mi fiereza, el pueblo aquel, sincero, generoso, ha dado abrigo al peregrino humilde: lo hizo maestro, que es hacerlo creador"[6]. Les deseo un futuro de maestros creadores. 


\section{Post scriptum}

Este breve texto se propone repensar lo dicho y escrito en una oportunidad muy singular por su significado y lugar: una cohorte de maestrandos que concluyó su cursado en el confín de lo habitable. Motiva esta relectura el supuesto que estas palabras también pueden servir de algo a otros compañeros que, por diferentes circunstancias, se encuentran frente a una situación análoga a la de los jóvenes colegas del sur: a punto de culminar un ciclo de su formación y enfrentados a las responsabilidades sociales en que los colocan los nuevos saberes que habrá de legitimar la academia. De alguna manera y tal vez pronto, otros les harán sentir que la formación recibida en el ámbito de lo público los ubica entre los referentes para las transformaciones de la educación que aspiran para ellos y sus hijos. A partir de ahora, el esfuerzo del orden de lo público que contribuyó a estos logros individuales aguardará con derecho alguna forma de involucramiento que intente estas transformaciones.

Si en alguna forma nos sentimos convocados a procesos de esta naturaleza, se trata de revisar cómo nos encuentra esta convocatoria: todo proceso de transformación requiere ampliar el ámbito de lo pensable y para ello habrá que poner en juego todo el acerbo que hasta ahora hayamos acumulado en conocimientos y saberes. Sin embargo, no se trata sólo de pensar sino de actuar, de intervenir, de participar de prácticas sociales que, como me gusta decir parafraseando a Freire, tengan la potencialidad de construir el inédito viable de una educación necesaria y soñada. Pero lo que es necesario para muchos es a veces indeseable para pocos y lo que es soñado por miles desvela a un puñado. Por esta razón, hacer viable lo inédito en el territorio de la educación puede implicar fuertes resistencias que hacen de cada acto educativo un acto político. Actuar en estas condiciones implica entonces asumir riesgos y requiere de la convicción y la pasión de toda empresa arriesgada.

Por esto me pareció necesario explicitar que este texto fue escrito para quienes creen que vale la pena correr algún riesgo en la aventura de educar.

Disponerse para la aventura, transformar la propia vida en una aventura, con todo lo que ello implica de azaroso, tiene que resultarnos atrayente, tiene que provocarnos alguna fascinación hacia un futuro que, como todo porvenir, es incierto. De ahí que la primera 
parte de este texto fuera una invitación a revisar nuestra disposición subjetiva para acometer el futuro junto a quienes necesitan otra educación, corriendo por ende su propia suerte. Suerte que además será la nuestra no sólo porque la compartamos con otros, sino porque habremos contribuido a dignificar nuestro propio trabajo y a legar a nuestras descendencias más queridas escuelas que algún día integren la memoria de lo entrañable y lo valioso.

Ahora bien, la argamasa con la que se construyen las transformaciones, aún las más pequeñas, es la propia realidad. Ella es la materia a transformar y ella es la que tenemos que tomar entre las manos para intentar darle otra forma. Esta realidad a veces huele a lodo que contamina y mancha, pero es la única materia posible de nuestros proyectos.

Un colega brasileño que participó del Seminario que provocó este texto dijo, citando a un connacional: un hombre vestido de traje blanco que pisa el barro y sale de él tan blanco como entró carece de poesía.

El barro con el que hay que amasar un futuro diferente es el presente. Pisar ese barro y tomarlo como materia prima de nuestras reflexiones y propuestas educativas, implica tener el valor de nombrarlo; nombrarlo supone reconocer su existencia y convertirlo en problema sujeto a debate.

Cuando se trata del pasado, el debate suele ser más previsible: se realiza sobre discursos más o menos consolidados y construidos a veces con congruencia y belleza. El presente, en cambio, nos implica de tal manera que nos impide tomar distancia para pensarlo, su devenir es incierto.

Nombrar aspectos de este presente, acontecimientos, personajes, procesos, es de alguna manera valorarlos en términos de su incidencia para la viabilidad de nuestros proyectos. $Y$ aquí, exactamente aquí, está el problema, porque lo que nombramos es decodificado por otros en términos de un pronunciamiento. 
Nombrar algunos procesos políticos y sociales que tienen lugar en nuestra América Latina y en Argentina como el contexto más amplio que condiciona esta viabilidad y expresar que algunos de ellos pueden resultar inesperados para el orden hegemónico, puede ser significado como una apuesta excesivamente arriesgada. Para algunos, parafraseando a Lechner (1988:187) el temor a las desgracias en que desembocaron sus sueños los censura en los deseos y, agrego yo, en la palabra. Nombrar es significar y significar implica un riesgo: el riesgo de equivocarse, el riesgo de nuevas frustraciones y, tal vez, el riesgo de alguna forma de represalia.

Quizás por eso algunos se contentan con ser dueños de lo que callan; tal vez por eso, algunos prefieren mantener el debate universitario, incluido el pedagógico, en términos lo suficientemente abstractos y ambiguos como para evitar estos riesgos. Modernos oráculos de Delfos, dejan que la corriente principal de la historia pase por las puertas de los templos académicos y se escurra por cunetas y acequias. Así, un presente confuso, contradictorio, multiforme y contrastante, que debiera ser la materia prima de investigaciones, debates y propuestas, corre sin salpicar los trajes y las túnicas níveas de intelectuales sin poesía ni coraje. Quizás no vean que entre los destellos del fango brillan los esfuerzos, las luchas y las esperanzas de quienes pujan por una educación inesperada para un tiempo inesperado.

El orden vigente no tolera sorpresas y prefiere educadores que ya no esperan. Este texto ha sido una respetuosa pero enfática invitación a reflexionar al respecto, proponiendo además algunas líneas de trabajo intelectual para sumar nuestro esfuerzo y nuestra lucha a los que se obstinan en esperar.

"Vamos a clavar los ojos más allá de la infamia, para adivinar otro mundo posible" (Eduardo Galeano: Patas arriba - La escuela del mundo al revés).

BIBLIOGRAFÍA Y DOCUMENTACION CONSULTADA:

- Argumedo, Alcira: Los silencios y las voces en América Latina, Ediciones Colihue, Buenos Aires, 2004. 
- Cantero, Germán: Educación popular en la escuela pública: una esperanza que ha dejado de ser pura espera; en "Igualdad y Educación”, Pablo Martinis y Patricia Redondo (comps.); Del Estante Editorial, Buenos Aires; 2006.

- Cantero, Germán: "La gestión escolar en condiciones adversas: escuelas que interpelan, orientan y reclaman"; en Pro-Posiçōes, revista quadrimestral da Facultade de Educaçāo; UNICAMP, vol. 8, №3 marzo, 1999; Campinas, SP, Brasil.

○ Dussel, Enrique: Política de la liberación; Editorial Trotta, Madrid, 2007.

- Diario Clarín (Buenos Aires): selección de artículos publicados en el año 1997.

- Freire, Paulo: Política y educación; Siglo XXI Editores, México, 1996.

○ Gabeta, Carlos: "Populismos", en Le Monde Diplomatique, Buenos Aires, junio 2006.

- Lechner, Norbert: Los patios interiores de la democracia - Subjetividad y política; FLACSO, Santiago de Chile, 1988.

- Merklen, Denis: Vivir en los márgenes: la lógica del cazador. Notas sobre sociabilidad y cultura en los asentamientos del Gran Buenos Aires hacia fines de los '90; en "Desde abajo", Maristella Svampa (editora); Editorial Biblos / Universidad Nacional de General Sarmiento, Buenos Aires, 2000.

○ MST Informa, Año V - № 119; 20 de junio de 2006.

○ Nassif, Ricardo: “José Martí - 1853 - 1895”, Revista Perspectivas, UNESCO, París; vol. XXIII, № 3 4, 1993.

- Sotolongo Codina, Pedro L. y Delgado Díaz, Carlos J.: La revolución contemporánea del saber y la complejidad social; CLASO Libros, Buenos Aires, 2006.

o Tamarit, José: Poder y educación popular; Libros del Quinquincho, Buenos Aires, 1992.

o Williams, Raymond: Marxismo y literatura; Ediciones Península, Barcelona, 1980.

[1] Texto preparado con motivo de la intervención en un panel en oportunidad del II Seminario Internacional "EDUCACIÓN Y RESPONSABILIDAD SOCIAL"; en el ámbito de la Maestría en Educación, sedes Ushuaia y Río Grande, organizado por la Universidad Nacional de Entre Ríos y el Polo Universitario Fueguino Ministerio de Educación de la Provincia de Tierra del Fuego, Antártida e islas del Atlántico Sur; Ushuaia, 7 y 8 de septiembre de 2007.

[2] Enrique Dussel: Política de la Liberación; Editorial Trotta, Madrid, 2007, pág. 498 y siguientes.

[3] MST Informa, Año V - № 119 - Terça-feira, 20 de junio de 2006 (Publicación quincenal del Movimiento de los Trabajadores Rurales Sin Tierra, enviada por correo electrónico). 
[4] Ver Carlos Gabetta: “Populismos”, Le Monde Diplomatique, junio 2006, pág.3.

[5] De Sousa Santos, B (2000 y 2005) citado por Dussel, Enrique; op. cit., pág. 557.

[6] Extraído del texto "José Martí - 1853 - 1895", de Ricardo Nassif, publicado en la Revista Perspectivas, de la UNESCO, París; vol. XXIII, № 3-4, 1993.

volta

file://C:|Documents and Settings\AdministradorlMeus documentos\Minhas Webs\NED... 11/9/2008 